\title{
A ALTERNATIVA COMO CATEGORIA EM LUKÁCS: A CAPTURA DAS MEDIAÇÕES HUMANO-GENÉRICAS
}

\author{
Sonia Regina LANDINI ${ }^{1}$
}

- RESUMO: Entre os desafios postos para as pesquisas em ciências humanas e sociais está a compreensão do cotidiano como espaço para a captura das formas de apropriação da realidade objetiva por parte dos sujeitos e, ao mesmo tempo, a identificação das respostas dos sujeitos diante das condições postas. Como categoria analítica, destacamos as reflexões de Lukács acerca da categoria alternativa, tomando-a como mediação entre teleologia e reflexo, no processo de objetivação da teleologia em causalidade posta.

- PALAVRAS-CHAVE: cotidiano, mediações, escolhas alternativas, humanização.

As formas de compreensão das relações sociais capitalistas e os possíveis meios de captura das mediações é tarefa árdua para os que investigam as práticas cotidianas no interior das instituições escolares. Os desafios concentram-se, em primeiro lugar, na compreensão do cotidiano como espaço para a captura das formas de apropriação da realidade objetiva por parte dos sujeitos e, em segundo lugar, nas respostas dos sujeitos diante das condições postas.

Tomamos o cotidiano como espaço de reprodução das condições capitalistas de produção e, ao mesmo tempo, de vivências contraditórias. Neste sentido, consideramos que a ação dos homens tem como ponto de partida a manutenção da vida e que por meio do trabalho o homem satisfaz suas necessidades, constroi uma relação intrínseca com outros homens, modificando a si e a realidade ao seu redor. No curso do desenvolvimento histórico

1 Professora doutora do Programa de Pós-Graduação em Educação da Universidade Federal do Paraná (UFPR). Artigo recebido em 11/2008 e aprovado em 10/2009. 
os homens tornam-se cada vez mais sociais, interagindo de modo que obtenham melhores condições para satisfazer suas necessidades. Dito de outra forma, o homem é expressão da relação entre sua singularidade e sua condição de gênero humano, da genericidade.

A realidade, cada vez mais social, põe-se na forma de uma gama imensa de possibilidades e alternativas, apresentando-se de modo gradativamente mais complexo.

Estão presentes nesse conjunto tanto a capacidade cognoscente do sujeito, quanto a objetividade social, ou seja, há uma unicidade e, ao mesmo tempo, um distanciamento entre sujeito e objeto. No contato entre sujeito e objetividade a consciência capta a realidade social, e atua sobre o sujeito e sobre esta mesma realidade.

A consciência não pode ser reduzida a uma dimensão psicológica e individual, existente per si, menos ainda como tão somente gnosiológica [...] Mas, como ser social, ela participa do processo social tornando-se um médium do movimento, um médium da história, que para além de adensar a dimensão gnosiológica, não negando a razão, nem uma teoria do conhecimento da realidade, [...] sofre alterações qualitativas originárias do fato social, ao mesmo tempo, interfere no fato social, modificando-o, segundo a linha de desenvolvimento, sempre contraditória, do complexo social. (Silva Jr. \& Gonzalez, 2001, p. 108)

Tendo em vista a racionalidade objetiva de uma dada sociedade, em um dado momento histórico, o homem reafirma-se como ser social, atuando no desenvolvimento de sua humanidade enquanto singular e gênero humano por meio do trabalho, ou seja, por meio de sua prática social. Aqui se processa um movimento de transformação tanto na esfera do sujeito singular, como na esfera social. Portanto, "[...] o trabalho é a mediação fundante da distinção, e concomitante articulação, entre as esferas da subjetividade e objetividade" (Lessa, 1997, p. 93).

Sob a égide do capital, no entanto, a racionalidade centrada na mercadoria, no trabalho abstrato - produtor de mais-valia -, impera e impulsiona os homens a agir de modo que reproduzam as condições de domínio de uns sobre os outros. Esta condição, posta no plano da imediaticidade, apresenta-se nos diversos planos da sociedade, buscando tornar hegemônica a condição de produção e intercâmbio de mercadorias, sem que se explicite o fato de ser a própria força de trabalho uma mercadoria, então trocada por um salário. Entre as esferas ideológicas está a educação institucionalizada, que tende a operar na imediaticidade, reproduzindo os valores postos socialmente. É preciso, no entanto, considerar esta relação em sua natureza conflituosa. A produção de mercadorias, no capitalismo, apresenta-se na forma de contradição entre a dimensão humana em sua relação com a natureza, transformando-a, e a dimensão social, na qual, no capitalismo, se im- 
põe o distanciamento do homem com relação ao objeto, com o processo e com o produto de seu trabalho. Esta contradição entre realização e não realização opera de modo que se geram no ser social conflitos e insatisfações, condição esta presente nas relações cotidianas.

Lukács em sua Estética (1974) afirma que é no cotidiano que todas as ações começam e terminam, sendo este, portanto, o locus de toda a vida contraditória do homem. É importante lembrar que para Lukács a vida humana tem como princípio ontológico fundamental o trabalho, tanto em sua expressão alienada, como em sua expressão realizadora. O trabalho é

[...] por sua essência uma inter-relação entre homem e (sociedade) natureza, tanto inorgânica (utensílios, matéria-prima, objeto do trabalho, etc.) como orgânica, interrelação que [...] antes de mais nada assinala a passagem, no homem que trabalha, do ser meramente biológico ao ser social. (Lukács, 1981, p. 14)

É nesse intercâmbio entre homem e natureza que a produção e reprodução da vida social toma corpo. "No trabalho estão gravadas in nuce todas as determinações que [...] constituem a essência de tudo o que é novo no ser social. Deste modo, o trabalho pode ser considerado fenômeno originário, o modelo do ser social..." (Lukács, 1981, p. 14).

No intuito de satisfazer suas necessidades, mediante as condições objetivas dadas, o ser humano é capaz de prever em sua consciência o fim a ser alcançado com sua ação (teleologia). Esse processo ocorre com base no reflexo na consciência de nexos causais (causalidade) presentes na realidade e que são postos em movimento tendo em vista o fim a ser alcançado, bem como as melhores maneiras para alcançar este fim. Assim, "[...] o significado da causalidade posta consiste no fato de que os aneis, as cadeias causais, etc., são escolhidos, postos em movimento, abandonados ao seu próprio movimento, para favorecer a realização do fim estabelecido desde o início" (Lukács, 1981, p. 71).

São as necessidades humanas, portanto, que caracterizam os processos de objetivação social e de socialização. Vale lembrar que, na condição de ser - racional e histórico -, o homem se põe as necessidades a que pode satisfazer. Neste processo são estabelecidas as mediações entre homem e realidade social/natureza.

Com o desenvolvimento das forças produtivas e consolidação do capitalismo, caracterizado pela exploração do trabalho não pago (mais-valia) e a consolidação da forma valor, estruturam-se mecanismos de reprodução social que visam a garantir esta exploração estabelecendo práticas alienadas/ estranhadas. Estes mecanismos de reprodução são introjetados por meio dos aparatos ideológicos e transformam-se em ações cotidianas, imperceptíveis. Vale ressaltar, no entanto, que os processos de reprodução tendem a 
garantir a manutenção da exploração, mas também acirram as desigualdades sociais, o que desencadeia conflitos sociais e lutas na direção de processos menos exploratórios de vida.

Aqui, com base em Lukács, podemos identificar a dualidade, posta com a sociedade de classes, entre indivíduo e gênero humano. É esta dualidade que caracteriza o cotidiano alienado. Ou seja, a cotidianidade expressa a pressão extrema aplicada socialmente na direção de uma prática individualizante, facilitadora da reprodução das condições de exploração. Dito de outro modo, as práticas cotidianas são contraditórias, visto que as objetivações do ser social também tendem à realização, desencadeando reações/mediações que retornam ao cotidiano alienado e enriquecem-no. A cotidianidade, marcada pelo individualismo e pragmatismo, gera formas de sua superação.

Nesse mesmo modo de refletir o cotidiano como espaço das práticas sociais contraditórias, Agnes Heller chama atenção para o fato de que a contradição posta na sociedade capitalista entre ser singular e genérico leva a práticas também contraditórias, mas que tendem ao senso comum, a uma compreensão alienada das condições dadas. Como características do cotidiano, Heller identifica as esferas não cotidiana e cotidiana. A primeira, a esfera da vida não cotidiana, representa o grau máximo de avanço social, relacionada às objetivações genéricas para-si (ciência, filosofia) que se caracterizam pela compreensão do caráter universal do gênero humano. A segunda, a esfera da vida cotidiana, diz respeito à reprodução da vida individual e coletiva marcada por objetivações genéricas em si. Neste âmbito, estão presentes as ações calcadas nos processos histórico-sociais que se caracterizam pela ação, por sentimentos e por pensamentos alienados, visto que a sociedade contemporânea impede a compreensão da genericidade e universalidade das práticas humanas.

Entre as características da vida cotidiana estão: o agir espontâneo, que consiste na ação sem a compreensão real da realidade, acrítica, que marca a maioria das atividades simples, mas também as que se tornam frequentes nas ações rotineiras de trabalho; a possibilidade, tendência a realizar atividades sem a certeza de seu resultado; o economicismo, busca segura de resultados; o pragmatismo, ação voltada para a prática, sem reflexões, na busca de resultado seguro; processos de ultrageneralização, ações baseadas em experiências prévias, individuais e sociais, e que se caracterizam pela imitação e/ou analogia.

Quanto mais o valor econômico assume preponderância, maior a tendência de reproduzir as formas de atuação que levam a práticas espontâneas, pragmáticas, por meio de mecanismos ideológicos.O cotidiano alienado, a cotidianidade, revela-se por práticas que tendem à manutenção do 
posto socialmente. No entanto, em uma compreensão dialética, evidenciase que

Na realidade, os homens não são manipuláveis indefinidamente em qualquer direção, pois sempre existe um ponto limite, um limite no qual deixam de ser objetos e se transformam em sujeitos. (Heller, 1972, p. 99)

Lefebvre também ressalta o cotidiano como expressão das práticas contraditórias que tendem à reprodução da lógica de mercado

[...] "cotidiano" designa a entrada dessa vida cotidiana na modernidade: o cotidiano enquanto objeto de uma programação cujo desenrolar é comandado pelo mercado, pelo sistema de equivalências, pelo marketing e a publicidade. Quanto ao conceito da "cotidianidade", ele ressalta o que é homogêneo, repetitivo, fragmentário na vida cotidiana: os mesmos gestos, os mesmo trajetos... (Lefebvre, 1989, p. 34)

Tal manipulação reflete-se nas práticas sociais e pode ser apreendida por meio das representações sociais, nas manifestações da relação entre percebido e concebido. O percebido é a interpretação do vivido, e o concebido é a expectativa - individual e social. No cotidiano as representações manifestam as relações entre concebido e vivido, tendendo à repetição e homogeneização. A cotidianidade para Lefebvre também assume a conotação de práticas manipuladas, programadas, caracterizadas: pela homogeneidade, por meio das normatizações e da burocracia; pela fragmentação, marcada pela divisão do trabalho; pela cisão entre sujeito e objeto, levando ao individualismo; pela hierarquização das relações de poder e dos saberes.

Dessas perspectivas, similares e ao mesmo tempo distintas, nos autores acima citados, temos no cotidiano a manifestação dos processos de alienação, considerando a condição entre exploração e desejos, ainda que inconscientes, de identificação com o trabalho, de realização.

\section{A alternativa como categoria em Lukács: a captura das mediações}

Tendo em vista as análises realizadas por Lukács no capítulo "O trabalho", na Ontologia do ser social, merece destaque que este autor desenvolverá sua análise com base no trabalho, visto da perspectiva ontológica, sem deter-se com profundidade, nessas investigações, nas formas capitalistas.

Aqui, como vimos anteriormente, opera um processo em que está presente a necessidade, que leva ao estabelecimento de um fim a ser alcançado (teleologia), propulsionando a captura das condições objetivas postas na realidade pela consciência (reflexo), as quais desencadeiam uma escolha planejada para a consecução do fim determinado. 
Lukács enfatiza que:

[...] quando o homem primitivo escolhe, de um conjunto de pedras, uma que lhe parece mais apropriada para seus fins e deixa outra de lado, é óbvio que se trata de uma escolha, de uma alternativa.

[...] mediante o reflexo [da realidade objetiva em sua consciência] e sua elaboração na consciência, devem ser identificadas certas propriedades da pedra que a tornam adequada ou inadequada para a atividade pretendida. Quando olhado do exterior, este ato extremamente simples e unitário que é a escolha de uma pedra é, na sua estrutura interna, bastante complexo e cheio de contradições. Com efeito, temos duas alternativas que têm relação de heterogeneidade entre elas. Primeira: é certo ou é errado escolher tal pedra para o fim posto? Segunda: o fim posto é certo ou é errado? É fácil ver que ambas as alternativas só podem desenvolver-se partindo de um sistema de reflexo da realidade (quer dizer, um sistema de atos que não-existem-em-si) que funciona dinamicamente e que é dinamicamente elaborado. Mas é também fácil de ver que só quando os resultados do reflexo não-existente se solidificam numa práxis estruturada em termos de alternativa é que pode provir do ser natural algo que exista no quadro do ser social, por exemplo, uma faca ou um machado, isto é, uma forma de objetividade do que existe total e radicalmente nova. (Lukács, 1981, p. 84)

O autor indica a alternativa como categoria mediadora no processo de objetivação da teleologia em causalidade posta, ou como mediadora do nãoser do reflexo e a causalidade posta, tendo em vista a escolha de uma entre várias possibilidades de ação. Esta escolha é sempre em algum grau consciente. A alternativa é o elo entre o reflexo na consciência e o resultado da ação humana por meio do trabalho. A potencialidade transforma-se em algo existente.

É importante destacar aqui que a ideia do reflexo da realidade na consciência para Lukács representa o "não-ser". É uma condição presente no processo de trabalho que reflete a potencialidade, uma possibilidade não objetivada. Ou seja, a condição objetiva, a materialidade, reflete-se na consciência e põe em atividade uma gama de possibilidades que podem ou não ser transformadas em uma nova objetividade. Portanto, há uma potência que é sempre uma potência de "ser" ou "não ser". Trata-se de um reflexo, e não o real. No entanto, o autor não nega aqui a não existência, mas ressalta a existência como potência que pode vir a ser transformada em uma nova forma de objetividade. O reflexo do real na consciência caracteriza-se pela íntima relação entre objetividade e subjetividade. Neste sentido, a consciência captura algo que está posto na realidade. Não se trata de puro pensamento, de uma consciência que apreende o real simplesmente por mera espontaneidade. "A imagem da realidade na consciência é o resultado de um processo muito complexo (e distante de estar totalmente aclarado hoje em dia). O homem não pode limitar-se a deixar que atuem sobre ele as im- 
pressões da realidade" (Lukács, 1982, II, p. 12). Ao mesmo tempo, não se trata de uma adaptação ao meio, capacidade esta que animais menos evoluídos realizam. De fato, a consciência captura ativamente a realidade cuja característica consiste na expressão da ação humana. Portanto, a realidade é histórica, marcada pelo modo com que os sujeitos agem e respondem às necessidades postas. Trata-se da captura de uma realidade concreta, histórica, determinada pelo fim a ser alcançado.

[...] Neste sentido, o reflexo tem uma natureza peculiar contraditória: por um lado, ele é o exato oposto de qualquer ser, precisamente porque ele é reflexo e não ser; por outro lado e ao mesmo tempo, é o meio através do qual surgem novas objetividades no ser social, por meio do qual se realiza a sua reprodução no mesmo nível ou em um nível mais alto. (Lukács, 1982, II, p. 26)

Tendo em vista o fato de ser a realidade objetiva resultado da ação humano-social, as escolhas alternativas também são resultantes destas condições, então refletidas na consciência. A cada novo processo de trabalho, novas decisões alternativas se põem, revelando uma maior complexidade do real e, consequentemente, das mediações que constituem a escolha alternativa.

A alternativa está intimamente relacionada às condições objetivas, à materialidade histórica, à subjetividade, não sendo em si a própria realidade, mas a apropriação da realidade que desencadeia a escolha por parte do sujeito. "A alternativa, que também é um ato de consciência, é, pois, a categoria mediadora por meio da qual o reflexo da realidade se torna veículo da criação de um existente (Lukács, 1981, p. 31).

Lukács ressalta que:

Quem trabalha deseja necessariamente o sucesso de sua atividade. No entanto, ele só o pode obter quando, tanto na posição do fim quanto na escolha dos meios, está permanentemente voltado para capturar o objetivo ser-em-si de tudo aquilo que se relaciona com o trabalho e para comportar-se em relação aos fins e aos meios de maneira adequada ao seu ser-em-si. Aqui não temos apenas a intenção de atingir um reflexo objetivo, mas também eliminar tudo o que seja meramente instintivo, sentimental, etc. e que poderia atrapalhar a visão objetiva. Precisamente assim nasce o predomínio do consciente sobre o instintivo, do cognoscitivo sobre o que é apenas emocional. (Lukács, 1982, II, p. 36-7; grifo nosso)

Para o homem primitivo, afirma Lukács, "[...] o objeto da alternativa é somente a utilidade imediata em geral, ao passo que na medida em que se desenvolve o caráter social da produção, isto é, da economia, as alternativas assumem um modo cada vez mais diversificado, mais diferenciado" (Lukács, 1982, II, p. 36-7). 
O fato de a economia configurar-se como desenvolvimento da técnica, sustentado pelas ciências, não indica a ruptura entre fim e meio, entre teleologia e alternativa. Lukács salienta que compreender as condições de desenvolvimento das forças produtivas e da técnica como determinante nas escolhas alternativas seria tão inadequado quanto compreender, em momentos prévios da história humana, a predominância da subjetividade sobre as condições objetivas. "A estas duas alegações deve-se objetar que as alternativas orientadas para o trabalho sempre são decididas em circunstâncias concretas, quer se trate do problema de fazer um machado de pedra ou um modelo de automóvel para ser produzido às centenas" (Lukács, 1981, p. 34).

No entanto, a economia baseada no valor imprime uma nova legalidade que interfere nas decisões alternativas, tornando abstrato o valor de uso, a utilidade do trabalho. A afirmação por meio do trabalho torna-se negação de si mesma e da condição humano-genérica. Este fato, característico da alienação do trabalho, imprime uma relação contraditória entre fim e meios. É preciso salientar, a produção de valores de uso mantém-se, levando a uma dupla condição: a contiguidade das posições teleológicas que transformam a natureza (aqui sempre entendida tanto no plano biológico quanto no social) e a "[...] ação sobre a consciência de outros homens com o fim de induzi-los às posições teleológicas desejadas". Neste sentido, "[...] o campo da economia socialmente desenvolvida contém posições de valor de ambos os tipos entrelaçadas de modos diversos, porém, neste complexo, também as do primeiro tipo, sem perder a sua essência originária" (Lukács, 1981, p. 75). Ou seja, entre as opções existentes, as escolhas realizadas pelos sujeitos também apontam para um devir humano autêntico, não alienado/estranhado. A superação da alienação/estranhamento só se efetivará com a produção coletiva de seres livres. Neste contexto, a ética tem papel central. Embora Lukács não tenha tido tempo hábil para desenvolver seus escritos sobre ética, aponta-se já na Ontologia do ser social (1981) uma potencial capacidade de o homem dominar seus instintos e paixões, bem como dominar as condições e características exteriores, definindo-se a captura da totalidade social.

Na sociedade contemporânea situa-se um dos mais caros desafios no plano da captura das mediações. As alternativas assumem a forma de valor moral, levando ao que Lukács denomina concepção trágico-relativista, o que revela a imediaticidade que os fenômenos expressam. Dito de outro modo, o risco de capturar a imediaticidade, e não as mediações, é reflexo da contraditória relação e sua manifestação valorativa para cada classe social.

A compreensão de Lukács é de que o desenvolvimento histórico-social do gênero humano e a culminação no desenvolvimento das relações capitalistas expressam a totalidade das condições humano-genéricas, totalidade esta contraditória. No entanto, o risco de perder de vista a totalidade e ana- 
lisar as condições imediatas desencadeadas no contexto das relações sociais leva a uma compreensão parcial e limitada da realidade. Nesta perspectiva, assume-se uma análise singular e não universal dos fenômenos sociais. Ou seja, abre-se espaço para enfatizar as decisões individuais, obscurecendo o desenvolvimento da sociabilidade e da genericidade humana, no que resulta uma análise parcial e, ainda pior, que reforça a valorização da individualidade em detrimento da universalidade do humano. Reforçam-se, deste modo, as análises alienadas acerca da realidade. Afirma Lukács (1981, p. CLXXIV):

Este desenvolvimento [humano-genérico] é hoje universalmente reconhecido no seu percurso e no seu ponto de chegada. Só que, frequentemente, é descuidado e como tal centralização das decisões sobre o indivíduo singular teria suas próprias raízes, e seus próprios motores reais, não no desenvolvimento imanente deste último, mas, pelo contrário, na crescente sociabilização da sociedade.

Lukács está tratando aqui de uma questão essencial: a relação entre singular-particular-universal. Em sua obra Introdução a uma estética marxista (1968), salienta a relação entre singular (indivíduo) e universal (a sociedade em seu todo), tendo como mediação o particular (relações sociais), como esfera da interconexão entre a totalidade social e o indivíduo, posta por meio das contradições entre esses dois polos. Aqui há uma importante consideração sobre a compreensão da universalidade enquanto expressão das múltiplas determinações. Ao mesmo tempo, da singularidade como expressão da apropriação pelo sujeito das condições concretas, e não como expressão abstrata do pensamento. Neste sentido, nem o concreto é fatal e definitivamente determinado economicamente - o que levaria à apologia do capitalismo e o fim da história -, nem o sujeito tem autonomia absoluta diante das condições concretas. Assim, Lukács afirma a necessidade de extrair-se

[...] da própria realidade as condições estruturais e as suas transformações históricas e [formular leis as quais devem abraçar] [...] a universalidade do processo, mas de um modo tal que deste conjunto de leis pode-se sempre retornar - ainda que frequentemente através de muitas mediações - aos fatos singulares da vida. (Lukács, 1968, p. 88)

Assim, a categoria alternativa apresenta-se como expressão da particularidade, das conexões entre singular e universal, entre as decisões singulares, sempre marcadas pela universalidade. Neste sentido, as práticas cotidianas são sempre marcadas pela condição particular, e as escolhas realizadas pelos indivíduos são expressões desta condição. Aqui tanto estão presentes as condições concretas apropriadas no plano da singularidade 
com base em sua condição no contexto social posto, como também, e por isto mesmo, estão presentes as contradições relativas à condição particular. Dito de outro modo, ao analisar as práticas cotidianas, temos que elas são marcadas pelo espontaneísmo, pela ultrageneralização, pelo pragmatismo, como indica Heller, e pelas relações de poder, pela burocracia, pela homogeneização, como aponta Lefebvre. Estas expressões cotidianas são, no entanto, sempre marcadas por escolhas que refletem esse estado de coisas, mas refletem também as insatisfações, os conflitos e as contradições.

A captura dessas manifestações revela a complexidade das relações sociais em um determinado momento histórico, dando suporte para a compreensão da realidade posta. Para que esta condição se efetive, é preciso considerar as mediações possíveis na própria realidade posta.

O agir social, o agir econômico dos homens abre livre curso para as forças, tendências, objetividades, estruturas, etc., que nascem decerto exclusivamente da práxis humana, mas cujo caráter resta no todo ou em grande parte incompreensível para quem o produz. Referindo-se a um fato tão elementar e cotidiano, como o nascimento da troca simples entre produtos do trabalho segundo a relação de valor, Marx diz: os homens "não sabem o que fazem, mas o fazem". (Lukács, 1979, p. 52)

Em contrapartida, não há imutabilidade no decurso da história humana. O fenômeno da alienação tem papel central na prática social no capitalismo, mas, e ao mesmo tempo, opera uma contradição capaz de levar a novas configurações práxicas. Dito de outro modo, tomando fenômeno e essência como inseparáves, temos que o fenômeno social que expressa a contradição também expressa a possibilidade de novas alternativas para a essência humana.

As contradições decorrentes do antagonismo entre realização e não realização, humano e desumano, carregam a potência transformadora que tem na alternativa sua expressão concreta. Com o desenvolvimento das forças produtivas e do conhecimento, aumentam as chances de percepção de pertencimento ao gênero humano e, do mesmo modo, as possibilidades alternativas:

[...] o desenvolvimento da sociabilidade na cooperação dos homens faz com que os estímulos ou desestímulos, a determinados tipos de práxis, a posições teleológicas, com as alternativas que são base destas, se centralizam cada vez mais sobre a consciência do eu dos indivíduos que devem agir. Pode-se afirmar: quanto mais desenvolvida, social, quanto maior na sua prática o afastamento da barreira natural, tanto mais explícita, multíplice, firme esta centralização das decisões sobre o eu que deve sempre realizar o ato. Este desenvolvimento é hoje universalmente reconhecido no seu percurso e no seu ponto de chegada. Só que, frequentemente, é descuidado como tal descentralização das decisões sobre o indivíduo singular teria suas próprias 
raízes, e seus próprios motores reais, não no desenvolvimento imanente deste último, mas, pelo contrário, na crescente sociabilização da sociedade. Quanto mais numerosas as decisões que o indivíduo deve tomar, quanto mais variadas elas são, quanto mais distantes se encontram da sua finalidade direta, quanto mais a ligação com elas é dada por complicados nexos de mediações, tanto mais o indivíduo deve formar em si uma espécie de sistema de disponibilidade a estas variadas, e entre si frequentemente heterogêneas, possibilidades de reações, se quer se conservar em tal complexo de obrigações cada vez mais numerosas e variadas. Portanto, o campo deste desenvolvimento é determinado socialmente, mesmo se no seu interior os diversos indivíduos que se encontram em situações "análogas" possam tomar decisões bastante diferentes. Porém, já que as consequências destas não dependem de si, tornase sempre mais intensa, por isso, a necessidade de harmonizar os diversos tipos de comportamento um com o outro, com as próprias necessidades, com as consequências sociais previsíveis, etc. E isto vale tanto para os atos cotidianos que se repetem continuamente, como para aquela mediação mais complexa. (Lukács, 1981, p. 137)

Com essas análises Lukács ajuda-nos a refletir sobre as práticas sociais, considerando-se a inter-relação entre essência e fenômeno, subjetividade e objetividade e como as formas de agir, as escolhas realizadas pelos sujeitos são marcadas pela relação dialética entre estas esferas. Tal contribuição permite-nos insistir na necessidade de capturar a historicidade das relações sociais, das práticas humanas, contrapondo-nos às análises tanto objetivistas, quanto subjetivistas das práticas humano-sociais. Não se trata de buscar respostas imediatas para a solução de problemas, mas de identificar as condições concretas em que as práticas cotidianas se põem e como as escolhas podem revelar caminhos para a construção de uma análise científica sobre a realidade.

LANDINI, Sonia Regina. The alternative category in Lukács: the capture of human generic mediations. Trans/Form/Ação, São Paulo, v.32(2), 2009, p.147158.

- ABSTRACT: One of the challenges in the human and social sciences researches is the understanding of the everyday life as field to identify and capture the forms of appropriation of the objective reality by social being. At the same time, the understanding and identification of the subjective answers in view of the objective conditions. As analytical category we detach the reflections of Lukács concerning the alternative category, taking it as mediation between teleology and posited structures, between process of objectivation of teleology and posited structures.

- KEYWORDS: everyday life, mediation, alternative, humanization. 


\section{Referências bibliográficas}

LEFEBVRE, H. Sociologias contemporâneas - Entrevistas do Le Monde. São Paulo: Ática, 1989.

. Critique de la vie quotidienne II - Fondements d'une sociologie de la quotidienneté. Paris: L'Arche, 1991.

LESSA, S. Trabalho e ser social. Maceió: Edufal, 1997.

HELLER, A. O quotidiano e a história. Rio de Janeiro: Paz e Terra, 1972.

LUKÁCS, G. Introdução a uma estética marxista: sobre a categoria da particularidade. Rio de Janeiro: Civilização Brasileira, 1968.

Princípios ontológicos fundamentais em Marx. São Paulo: Ciências Humanas, 1979

. Ontologia dell'essere sociale. Roma: Editori Riuniti,1981.

. Estética I - La peculiaridad de lo estético. Barcelona/México: Grijalbo, 1982.

SILVA Jr., J. dos R. \& GONZALEZ, J. L. C. Formação e trabalho - Uma abordagem ontológica da sociabilidade. 1. ed. São Paulo: Xamã, 2001. 